\title{
Beyond Attrition and Retention: Working With Students to Enhance the First Year Experience
}

\author{
Natalia Gerodetti, Darren Nixon
}

Leeds Beckett University, UK

\begin{abstract}
Student retention and attrition rates have been established as Key Performance Indicators (KPIs) for course teams in the Higher Education landscape in the UK. Against this quantified (and neoliberal) auditable undertaking, in this paper we offer an examination of a set of alternative qualitative efforts which are intended to improve the first year student experience by helping students transition into their course, and university life more generally. Working with students to enhance the first year experience is at the centre of our ontological position and we draw heavily on the idea of a "long thin" induction which continues throughout the first year at university. We explore the benefits of facilitating 'students as producers' and incorporating 'student intelligence' into university teaching and learning practices before presenting a series of activities that are designed to help students transition successfully and build a strong course identity. Having offered students different ways of structured integration into the course we reflect on how these activites can help first-year students develop the kinds of skills and knowledge base that contributes to a better experience of the transition and acculturation into university life in all of its facets.
\end{abstract}

Keywords: transition; games-based learning; students as producers; induction; mentoring. 


\section{Introduction}

Within the changing UK Higher Education landscape students' successful transition into university, measured by their ability to progress into the second year of study, has become a key performance indicator. Retention and attrition are significant issues for universities and higher education funding councils and increasing attention has been given to how to improve student retention and to explore the causes of attrition (Wilcox et al., 2005; O'Keefe, 2013). Student attrition costs universities in terms of lost revenue whilst also not reflecting well upon the institution (Yorke and Longden, 2007). Whilst non-continuation rates for undergraduate students vary according to discipline, a range of factors - both endogenous and exogenous - to the university itself are important.

Drop out rates in social studies across the UK are at 5.7\% (the same as law) (HESA, 2018). For the subject of sociology continuation rates (at the same institution) have been consistent between the years 2003-4 and 2012-13 at around 89\% (HEFCE, 2018). Russell Group universities have generally lower non-continuation rates (below 4\%) where post-1992 institutions have higher ones. From 2015-16 entrants, Leeds Beckett University retained $84.8 \%$ students (11.8\% left HE altogether, the remainder transferred to another institution) (HESA, 2018). For a variety of reasons, including the fact that the university has a higher proportion of students from disadvantaged background (as calculated by the POLAR system), student dis-continuation is slightly above sector average in our institution and student retention is therefore an issue for course management.

However, our focus here is less with the institutional frame and more on enhanching the first-year student experience, particularly the level of integration, connectedness, and involvement with the course and the ways in which this is an important determinant of their academic persistence and success (Yomtov et al., 2015). Thus, this paper charts how we have attempted to collaboratively address these concerns through staff-students projects exploring how the transition to university life might be smoothened through game-based learning, resulting in an 'extended' or 'long thin induction'.

\section{Attrition, Retention and the First-year Transition}

Experiences in the early weeks of university life are important in influencing students' decisions to withdraw from their course (Wilcox et al., 2005). Lack of perceived social support has been linked to the likelihood of students to drop out. It is widely agreed in the literature that the transition to university life presents both opportunities and a range of significant challenges for first-year students. They are required to negotiate a variety of new experiences in order to 'fit in' with both the academic and social aspects of university life (Wilcox et al., 2005). New students have to deal with factors such as relocation, separation from family and friends, living with strangers and adjustment to new expectations around 
independent learning and academic life more generally. These challenges substantially impact upon their sense of identity and belonging and can generate feelings of disorientation (Briggs et al., 2012), or isolation and loneliness (Scanlon et al., 2007). In this context establishing a 'new' identity and a sense of belonging through relationships with peers, and to a lesser extent staff, appear key (Wilcox et al., 2005; Scanlon et al., 2007).

In their small-scale qualitative research on first-years who withdrew from or stayed on their social science course, Wilcox et al. (2005) argue that retention issues are complex and multifaceted. Amongst leavers the main difficulties centered around social issues (making friends, feeling lonely and lacking emotional support), academic issues (course fit, expectations mismatch, independent learning) and material issues (accommodation, finance, location). In particular they emphasize the importance of social support and networks as $3 / 4$ of leavers mention difficulties with making friends. As Yorke and Longden (2007) argue in their review of research around retention, simply making friends is crucial to a successful transition into higher education.

In the context of wide-ranging changes to $\mathrm{HE}$, and particularly an increasingly diverse student body, attention has focused on how HE institutions might better understand student transitions and provide more appropriate student support. Here the induction period has been identified as important. O'Keefe (2013) argues that creating a sense of belonging by course tutors is crucial whilst, at the same time, avoiding information overload in the induction and the first weeks of study (Hamshire \& Cullen 2010) which students can perceive to be bewildering. Rather, using this period as a chance to build and establish positive peer friendships, coaching and mentoring relationships amongst students may prove particularly fruitful (Briggs et al. 2012).

In terms of creating a more positive transition, Yorke and Longden (2007) has argued that institutions are recognizing the value of a 'longer and thinner' induction experience that starts early and lasts longer than one week. This de-emphasizes the bewildering first week, and provides more opportunity for new students to assimilate and make sense of the information provided. Kift et al. (2010) propose a 'transition pedagogy' that encourages students to become members of a community of learners and recognizes that first-year students have particular needs based on the transition experience. This approach likewise sees transition not as an introductory event, but as a year long process with curriculum as a thread to which other aspects of transition must be added (Bowles et al., 2014).

These findings have led us to focus on incorporating student intelligence and experience into the production of a range of induction activities that are broadly aimed at enriching the first-year student experience. Our aim has been to build a strong course identity - feelings of inclusion and involvement in the course - through establishing greater student peer 
relationships and developing staff-student collaborative projects that provide a genuine opportunity for students to shape the learning and teaching stragtegies on their course.

\section{Students as Producers of Games}

We have discussed elsewhere some of the key tenets of the 'students as producers' discourse (Gerodetti and Nixon, 2014). One of its foundational principles is to explore ways in which 'student intelligence' can be incorporated into teaching and learning practices 'through collaboration with academics on research projects of real intellectual value' (Neary, 2012: 2). We have successfully applied the principles of this discourse in a previous collaborative project with students who created games that can be used to teach research methods and ethics (Gerodetti and Nixon, 2014). A key observation from our game-design workshops and watching our students play the games with other students during testing was the positive social relationships that were built amongst students from different year groups both making and playing the game. Older students reveled in coaching and mentoring less experienced students, who appeared to feel reassured by the advice they received.

Unlike lecturer designed games, we priortised our students' experiences in giving them the task to design a game that could be played during induction which would not only introduce first-year students to common concerns and problems but also encourage them to collaboratively construct solutions to dilemmas posed in the game. The game was designed by sociology students (from different year groups) with no background in game design. The learning objectives were defined collectively as; to develop an awareness of issues commonly encountered by first-year students; to develop skills and knowledge to solve such issues; and to develop a student community based on shared values. This final objective shaped the decision to develop a new traditional game which could be played in groups. In building collective knowledge and addressing common students issues, a student community with shared values and shared knowledge may be fostered through playing the game. These learning objectives were achieved through the content of the game and collaborative play.

\section{The Transition Game}

'University Challenges' is an interactive, competitive and collaborative board game (Figure 1) in which students attempt to accumulate credits by moving around a board and be the first to 'pass-progress' (to the second year) to thereby win. The game is built on a gamesbased learning paradigm which, in this case, is not about using 'serious games' to provide learning opportunities for course content. Instead the game aims to provide learning opportunities around the transitional aspects of becoming a learner in a contemporary 
Higher Education system. The game therefore mirrors some of the structuring aspects of first year student life requiring each group/team to complete six modules of the course structure in order to reach the goal 'pass-progress'. This refers to the exam board terminology used at our university to indicate a student's entitlement to proceed into the second year of study.

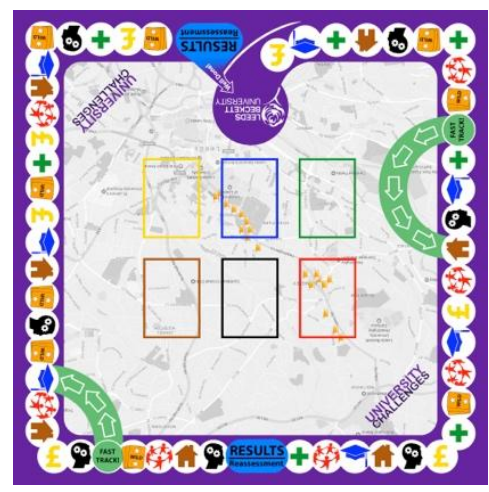

Figure 1: The University Challenges Board Game

Equally significant, the game allows students to become accustomed to aspects of student life through a mixture of luck and problem solving components, which intend to increase their knowledge and strengthen collaboration and social connections amongst first-year students. Our peer-competitive board game introduces students to the specificities of becoming a student and is organized around six key areas of student life identified by student game designers, namely: having to manage one's own finances, dealing with accommodation issues, establishing new social connections and maintaining old ones, social and peer aspects of being a student, knowledge about wider health and safety aspects and, finally, academic conventions and frameworks as they affect students.

Given the characteristics of first-year transition experiences discussed above and the positive social and interactive attributes associated with new-traditional games (Gerodetti and Nixon, 2014), a 'transition game' or a game that is played during a long induction process that addresses issues new students face offers a range of potential social benefits. These include providing a context for socializing and building relationships with new course mates, developing a reassuring awareness that others share their fears, information sharing and collective and collaborative problem-solving.

The game is in its third year of being played and the cohort from 2018-19 played it in induction week. $80.7 \%$ felt the game provided useful information about the university which was embedded into the game. In relation to social integration $84.4 \%$ students felt it was useful for meeting other students and $73.6 \%$ thought it was useful for (starting) to build 
new relationships. Equally, the collaborative aspects were valued by $77.2 \%$ of first year students and $65 \%$ thought it contributed to a sense of belonging to the course. Given this was a one off intervention in induction week it is perhaps more useful to point out that new first years were impressed with the fact that previous students had designed the game and most liked 'hearing real life advice from the third years'. Other aspects they most liked about the game were: 'getting to know other students', 'talking to peers' and the fact that 'Nobody was scared to speak up because it was in the context of a game rather than a group of strangers'.

However, group wide single interventions are limited in their scope and impact and thus are best utilised as part of a of suite of interventions aimed at embedding students within their course. Other meachanisms to foster first years' integration, connectedness, and involvement with the course and their peers occurs through an 'away day' during our 'sociology festival week' in week 7 of teaching during which students walk in groups with tutors to an Industrial Museum where teaching activities take place. The walk provided a non-campus based opportunity to socialise with other students and also, importantly, engage in some bodily exercise; something that is inceasingly being recognised for having a contribution to wellbeing which can be framed by theories of restorative environments and therapeutic landscapes (Bornioli et al., 2018). Further tasks designed to foster students' connectedness and involvement are group projects carried out during the first semester, one of which is also tied to a reflective task on the learning progress of students - the contents of which are also used to advise students in need of the existing mentoring programme.

\section{Peer Mentoring}

A peer mentoring programme was piloted in 2017 and has been rolled out more widely within the sociology course. Contrary to the skills focused library mentoring programme in existence a more course focused mentoring programme has the benefit of matching students with peers from within their course, thereby strengthening the connectedness to the course itself. In doing so we follow the idea that a peer mentor is someone who provides support, guidance and practical advice to a mentee who is close in age and shares common experiences and characteristics through intentional matching (Beltman and Schaeben, 2012).

The mentoring scheme is voluntary for both mentors and mentees and in the past year 12 mentors have been trained to support and guide students in lower years. Despite an initial call for first year students to opt into the mentoring scheme, only 8 students (of a cohort of 120) applied (and were matched with a mentor). This is not surprising given that evaluations of mentoring schemes point to difficulties in take up or maintenance of mentoring relationships on behalf of potential mentees (Andreanoff, 2016). Thus, in 
response, an adaptive approach to the mentoring scheme was employed (which is still in progress) whereby students who express (such as in their reflections) or exhibit difficulties during the semester are approached with the suggestion to get assistance from a mentor. This approach has resulted in 10 more students engaging with the mentoring scheme and early evaluations suggest that both mentors and mentees find the scheme beneficial.

\section{Conclusion}

Transition into HE is not just marred with problems and it is worth remembering that most students transition 'successfully'. Students are an increasingly diverse body that experience transitions in different ways and with differential access to resources and social and cultural capital. Research on first-year transitions and retention suggests the relationship is complex and multi-faceted. Nonetheless it is possible to identify common issues that cut across both 'stayers' and 'leavers' experiences, but perhaps particularly affect 'leavers'; these are namely 'social' aspects as well as 'academic' and 'financial' ones. Our multimodal interventions and activities are designed so that the diverse body of students who start the course can engage with several activities which can help connect, engage and support a wide array of students, many of whom are increasingly arriving with mental health issues. Peer-to-peer activities also allow students to build their own tacit knowledge and experience of transitioning. Along with gaining deeper knowledge of 'student life', it is our contention that our various activities also encourages positive social interaction amongst first-year students (and peers in older cohorts), ultimately helping the development of the peer support and friendship networks that appear so important for the successful transition to university life.

\section{References}

Andreanoff, J. (2016). Coaching and Mentoring in Higher Education. London: Palgrave.

Beltman, S., Schaeben, . (2012). Institution-wide peer mentoring: Benefits for mentors. The International Journal of the First Year in Higher Education. 3(2), 33-44. Doi: 10.5204/intfyhe.v3i2.124.

Bornioli, A., Parkhurst, G. \& Morgan, P. (2018). The psychological wellbeing benefits of place engagement during walking in urban environments: A qualitative photo-elicitation study. Health and Place, 53, 228-236. doi: 10.1016/j.healthplace.2018.08.018

Bowles, A., Fisher, R., McPhail, R., Rosenstreich, D. \& Dobson, A. (2014). Staying the distance: Students' perceptions of enablers of transition to higher education. Higher Education Research and Development, 33(2), 212-225. doi: 10.1080/07294360.2013.832157.

Briggs, A.R.J., Clark, J., \& Hall, I. (2012). Building bridges: Understanding student transition to university. Quality in Higher Education, 18(1), 3-21. Doi.org/10.1080/13538322.2011.614468 
Gerodetti, N., \& Nixon, D. (2014) Proceedings from $8^{\text {th }}$ ECGBL: Students as producers: Designing games to teach social science research methods and ethics. Reading: Dechema.

HESA (2018). UK performance Indicators 2014/15: Non-continuation rates, Available at: https://www.hesa.ac.uk/data-and-analysis/performance-indicators/non-continuation.

HEFCE (2018) Non-continuation Rates and transfers. Retrieved from: http://www.hefce.ac.uk/analysis/transfers/nc-rates/

Hamshire, C., \& Cullen, R. (2010). Developing a spiraling induction programme: A blended approach. In K. Anagnostopoulou \& D. Parmer (Eds), Supporting first year Student experience through the use of learning technologies (pp. 32-34). Middlesex: HEA.

Kift, S., Nelson, K. \& Clarke, J. (2010). Transition pedagogy: A third-generation approach to FYE: A case study of policy and practice for the higher education sector. International Journal of the First Year in Higher Education, 1(1): 1-20. doi.org/10.5204/intjfyhe.v1i1.13

Neary, M. (2012). Teaching politically: Policy, pedagogy and the new european university. Journal for Critical Education Policy Studies, 10(2), 233-257. URL: http://www.jceps.com/archives/715

O'Keefe, P. (2013). A sense of belonging: Improving student retention. College Student Journal, 47(4), 605-613.

Scanlon, L., Rowling, L., \& Weber, Z. (2007). 'You don't have like an identity...you are just lost in a crowd': Forming a student identity in the first-year transition to university. Journal of Youth Studies, 10(2), 223-241. Doi.org/10.1080/13676260600983684

Wilcox, P., Winn, S., \& Fyvie-Gauld, M. (2005) 'It was nothing to do with the university, it was just the people': the role of social support in the first-year experience of higher education. Studies in Higher Education, 30(6), 707-722. Doi.org/10/1080/030750705003440036

Yomtov, D., Plunkett, S., Efrat, R. \& Marin, A. (2015). Can peer mentors improve firstyear experiences of university students?. Journal of College Student Retention: Research, Theory and Practice, 19 (1), 25-44.doi.org/10.1177/1521025115611398

Yorke, M., \& Longden, B. (2007) The first-year experience in higher education in the UK, HEA. Retrieved from: http://escalate.ac.uk/downloads/3365.pdf 